\title{
Analysis of charge exchange in a single-cylinder of spark ignition engine
}

The article presents the results of tests carried out on a single-cylinder of spark-ignition engine. The charge exchange process in the combustion chamber is very important to determine the possibility of improving the overall efficiency of the engine. Describes of impact modifications engine on open indicator diagrams. Open indicator diagrams show that the higher compression ratio is assumed, the higher the pressure in the system is. First parts of the research describes analysis of charge exchange on not working engine. Results of research presents different open indicators diagrams. Then the pressure results were obtained on the working engine. The possibilities of improving the overall efficiency of the engine by reducing the pumping loss, associated with the replacement of the air fuel mixture, were presented. The article describes the modification of a spark-ignition engine that affects the pressure change in the combustion chamber. The use of innovative methods of regulating the compression pressure gives a lot of positive effects.

Key words: engine, efficiency, compression ratio, pressure

\section{Introduction}

New design solutions are constantly sought with the purpose of improving the performance of the internal combustion engines. According to the report by the Japanese engineers in the :Research Association of Automotive Internal Combustion Engine: (AICE), research will soon lead to the development of upgrades in the design of internal combustion engines, in which the overall efficiency will be around 50\% [6]. However, considerable efficiency of combustion engine does not solve the problem of its poor performance within low and intermediate loads. On the other hand, a direct increase in the efficiency of an internal combustion engine can lead to a decrease not only in terms of the use of hydrocarbon fuel, but also of harmful substances contained in the exhaust gases. According to forecasts by the International Energy Agency (IEA), 70\% of all passenger cars and light commercial vehicles produced will be powered by ICEs, and specifically, spark ignition engines. At the same time, it is forecasted that by 2050 approximately $50 \%$ of all cars will comprise a traditional ICE.

Internal combustion engines that apply the control of variable compression ratio technology provide an example of a design that combines the traditional solutions and the use of a up-to-date control strategy. Research team from the French company MCE-5 Development S.A. has been concerned with such solutions for several years. Their achievements are significant, as the team reported a $31 \%$ reduction in fuel consumption coupled with a $16 \%$ increase in engine power output, and a $62 \%$ increase in torque [11]. The Toyota team is trying to achieve similar results by synchronizing the combustion engine operating according to the Atkinson cycle in a hybrid power unit as part of the familiar solution already applied in the Toyota Prius car. It also tries to adjust the cycle of the internal combustion engine by applying the variable compression ratio as a result of the design changes, such as in the case when crankshaft axis and cradle axis are offset and the cradle is Pivoted to adjust the compression ratio - VCR Mechanism Assessment. Besides, the innovative trend is based on the solution of Enver company from the USA which focuses on interesting and tangible solutions. Among such designs, it is noteworthy to mention ones that were developed jointly by Nissan with VW, and currently used in the Infinity passenger cars, not to mention other solutions designed by SAAB and GM. However, despite significant advantages, not all of the above solutions find automotive application, just like the ones that have been achieved in France, as the service life and reliability of the newly designed engines form an obstacle in implementation. Hence, in the study reported by Boretto [7], a MDE (Midsize Diesel Engine) was developed and follows a completely new design approach, including downsizing and downspeeding strategies. It is impossible to list the solutions provided by the VW form with regard to the EA288 3B Generation engines that allows the combustion of lean air-fuel mixtures at low and intermediate engine loads, and this solution achieves the efficiency of the internal combustion engine of above $44 \%$. This is confirmed by the results in which the presented engine reduces $\mathrm{CO}_{2}$ road emissions in the NEDC test by $10-12 \mathrm{~g} / \mathrm{km}$.

Due to the fact that throughout road tests, it is most common to apply the low ranges of rotational speed of the crankshaft and intermediate loads [10], the increase in the energy efficiency of existing ICEs will provide the opportunity to apply them as the principal source of power in vehicles for many years to come. This aspect of the development of modern internal combustion engines is important in the conditions when new solutions focus on the protection of the environment. The reduction of fuel consumption is directly related to the decrease of carbon dioxide emissions to the environment and emission of harmful substances contained in the exhaust gases.

The paper focuses on one of the major trends that provide better efficiency of the internal combustion engine in the range of low rotational speed of the crankshaft and intermediate load. The paper focuses on the potential for reducing losses during the charge-discharge cycle throughout the intake stroke in an internal combustion engine comprising a throttle in the intake manifold.

\section{Charge exchange cycle in internal combustion engine}

The cylinder filling process takes the interval from the opening of the inlet valves to the instant when they are 
closed. In other words, this is the interval in time from the end of the exhaust stroke through the intake stroke and ending at the instant when the compression stroke is initiated. Fresh charge is injected into the cylinder as a result of the instantaneous differential pressure. The course of these pressure changes results from dynamic gaseous phenomena in the inlet and outlet channels as well as the motion cycle of the piston in the cylinder.

The factors involved in the thermodynamic state of cylinder filling include:

- temperature of new charge,

- temperature at the beginning of the filling process,

- pressure of exhaust gases,

- pressure at the beginning of the compression cycle.

The parameters of the exchange of gas and fuel in ICEs constantly change corresponding to the charging cycle in the cylinder. When the outlet the pressure decreases, so does the temperature. To evaluate the process of exchange of gas and fuel in ICEs, it is necessary to determine its thermodynamic parameters such as pressure and temperature and the volume of fuel in the cylinder. When the compression ratio is increased, the area of the heat absorbing surface decreases, which is associated with an increase in temperature [1].

The filling of the engine cylinder is assessed by the volumetric efficiency. The formula for the volumetric efficiency takes the form:

$$
\eta_{\mathrm{v}}=\frac{\mathrm{m}_{\mathrm{r}}}{\mathrm{m}_{\mathrm{s}}}
$$

where $\mathrm{m}_{\mathrm{s}}=\mathrm{V}_{\mathrm{s} \rho \mathrm{o}} \cdot \rho_{\mathrm{o}}=1.169 \mathrm{~kg} / \mathrm{m}^{3}, \mathrm{~m}_{\mathrm{r}}-$ mass of delivered charge, $\mathrm{m}_{\mathrm{s}}$ - theoretical mass of charge from a specific cylinder capacity and air density.

The increase of the rotational speed of the crankshaft is accompanied by a greater flow resistance, and the charge can even enter the intake manifold. These factors affect the deterioration of the volumetric efficiency. Figure 1 shows the relation between volumetric efficiency and the rotational velocity of the crankshaft.

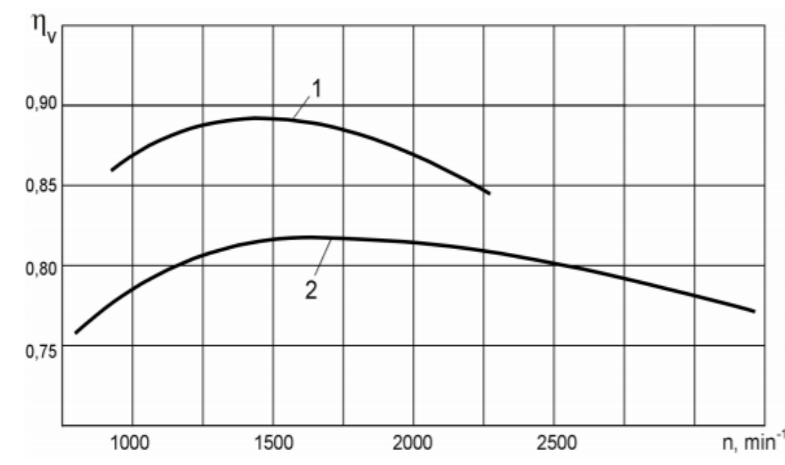

Fig. 1. Dependence of volumetric efficiencyon the cranskshaft velocity for respective types of engines: 1 - self-ignition engine, 2 - spark-ignition engine [2]

In order to be able to control the charge exchange in an ICE to a greater extent, it is necessary to implement the degree of freedom into the engine control system so that it is possible to control the effective pressure increase in the cylinder. As a result of the continuous increase of the com- pression ratio in the engine, the performance is not feasible nor cost-effective [2]. In a spark ignition engine, the potential to increase the compression ratio is limited mainly by the occurrence of the phenomenon knowns as knocking combustion, which can lead to catastrophic failure to the engine. The strength and the occurrence of mechanical losses as a result of too high compression ratios lead to the design of spark-ignition engines with the values of compression ratios in the range from 9 to 14. The notion of engine induction refers mainly to the measurements of cylinder pressure. The adequate use o of the induction techniques provides the opportunity of observing phenomena occurring in the combustion chamber at a low cost. The pressure measurement usually involves a full engine cycle.

As a result of changing the compression ratio, is the control the effective pressure in the cylinder is directly affected. The pressure course in the cylinder provides a series of different analyzes. The parameters of the indication can be divided into two categories:

- indirect parameters of the induction,

- direct parameters of the induction.

The difference between direct and indirect parameters means that the direct indication parameters are determined on the basis of the pressure curve derived from a single cycle. Indirect indication parameters require a number of calculations that are needed to determine them.

The control of the effective coefficient of pressure increase in the cylinder is related to the maximum pressure in the cylinder and after averaging it represents the characterristic of the operation of the internal combustion engine in the form of its power, which forms an important characterristic of the engine performance.

Heat transfer takes place between the charge in the cylinder and the cylinder walls and the piston crown. The heat spreads with variable intensity and in a variable direction; therefore, the compression curve taken in the theoretical cycle differs significantly from the compression curve presented in the actual cycle. The curve that describes compression is defined by a constantly changing exponent in a closing range of 1.1 to 1.5 [5]. The following equation defines the parameter of the compression end:

$$
\mathrm{p}_{\mathrm{c}}=\mathrm{p}_{\mathrm{a}} \cdot \varepsilon^{\mathrm{m}_{1}}(\mathrm{MPa})
$$

where: $\mathrm{p}_{\mathrm{a}}$ - pressure at the beginning of the compression stroke $(\mathrm{MPa}), \mathrm{m}_{1}-$ mean exponent of the polytropic compression curve, $\varepsilon$ - compression ratio.

\section{Experimental setup and test object}

The test object involved a single-cylinder spark ignition ICE with a displacement equal to $570 \mathrm{~cm}^{3}$. This engine included a modified cylinder head design, including:

- addition of an additional bleed channel in the head of the engine to couple the combustion chamber with the environment.

- adding an additional pressure measurement sensor in the combustion chamber.

In this way, the possibility of taking pressure measurements in the combustion chamber was implemented and the possibility of supplying or removing an additional air volume to the charge fed to the engine cylinder during the 
intake or compression stroke was introduced. Fig. 2 presents the section of the head with the integrated bleed.

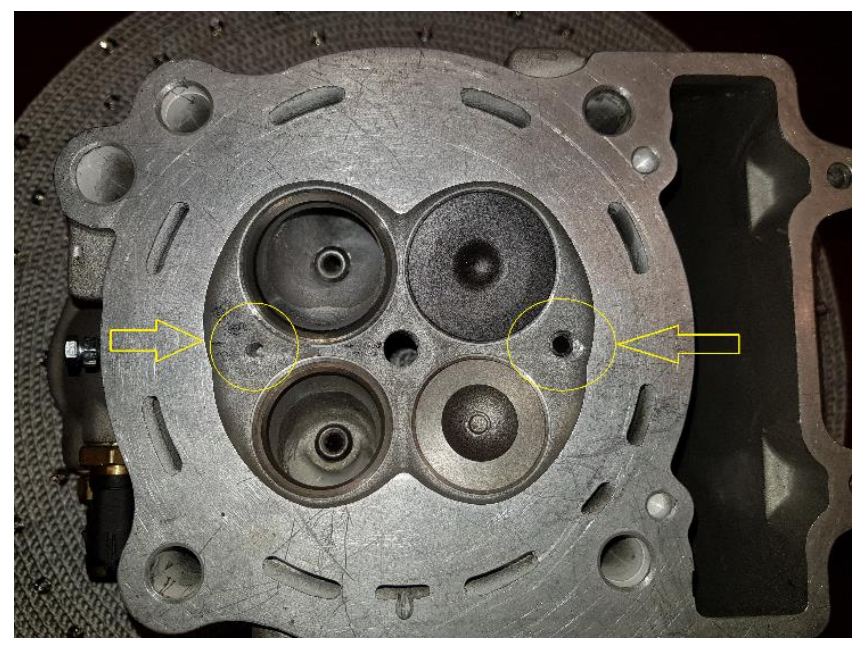

Fig. 2. Combustion engine cylinder head: view of modified head
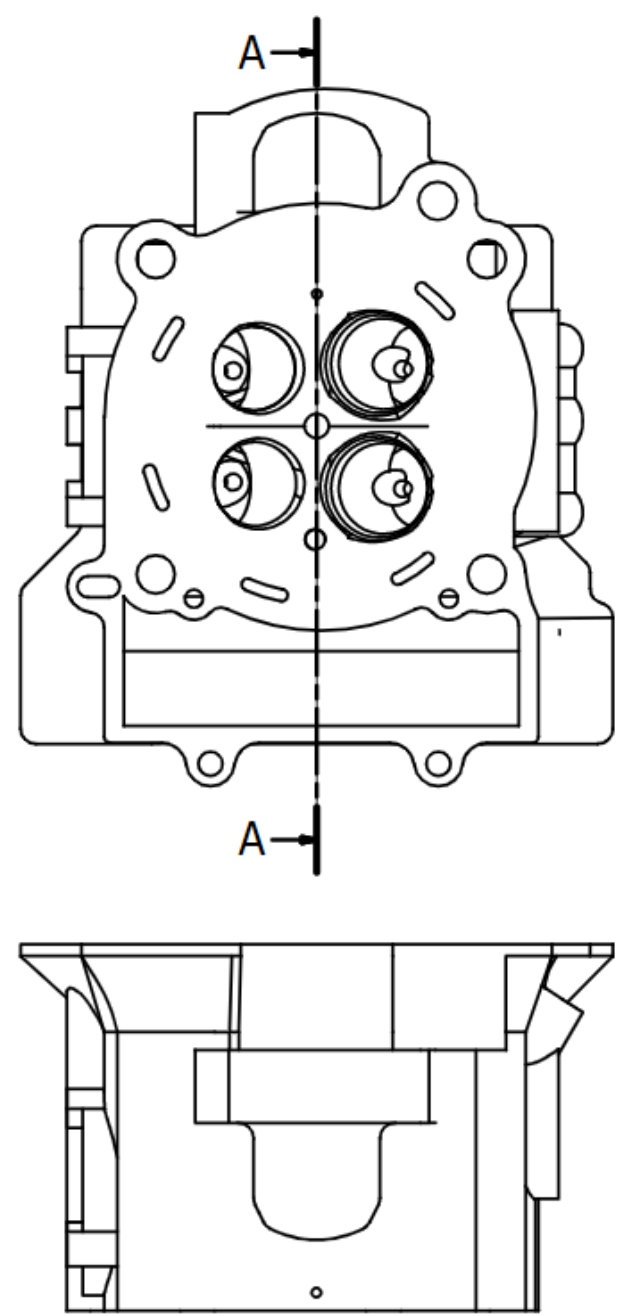

Fig. 3. Model of engine head

Experimental tests have been carried out on a dynamometer comprising an electrodynamic brake that provides conditions for both driving and braking of the investigated engine. A photograph with the engine installed during the test is shown in Fig. 4, it is coupled with a brake by means by means of a flexible clutch with non-axial compensation. This solution provided the manner in which axial vibrations of the crankshaft of the internal combustion engine could be compensated.

Throughout the tests, special attention was paid to the process of load exchange in the intake and compression stroke, hence the tests were carried by application of the ICE, but without power input from an electrodynamic brake. The engine is additionally equipped with sensors for the measurement of the following engine operating parameter:

- pressure in the combustion chamber,

- velocity and position of the crankshaft,

- velocity and position of the camshaft,

- throttle position in the intake manifold,

- pressure in the intake system [8].

Due to the fact that this internal combustion engine does not contain a camshaft position sensor, a decision was made to additionally install it (as marked in Fig. 4). The synchronization of the signals from the camshaft position sensor and the crankshaft position sensor provided an adequate determination of individual strokes in the engine. In order to ensure precise and repeatable throttle position in the intake manifold, a control system was designed and assembled to apply Arduino Uno microcontroller.

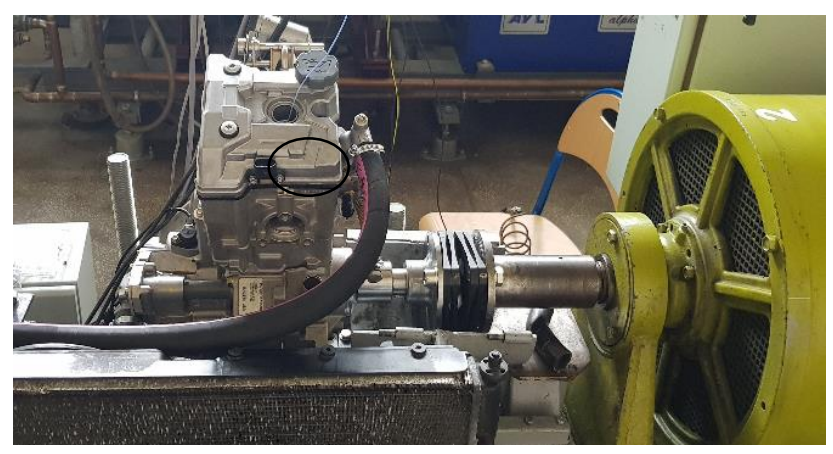

Fig. 4. Experimental setup installed at the dynamometer

\section{Experimental study}

The increase of the volumetric efficiency in the cylinder was implemented by introducing to the processes of charge exchange of the an additional possibility of feeding or bleeding some of the fuel and air mixture from the cylinder. For this purpose, an additional channel was applied, which included the possibility of adjusting the diameter of the channel leading to cylinder head. Throughout the experimental tests, series of measurements were carried out, which involved changing the diameter of the bore in the cylinder head by attaching previously fabricated orifices. The research comprised several stages, the first of which involved the measurement of pressure in the engine in the condition of the rotational speed equal to $1000 \mathrm{rpm}$ with a closed valve $(\mathrm{DCH})$ in the cylinder head. Two extreme pressure courses inside the cylinder were recorded, for the closed throttle (TPS 0\%) and for the open throttle (TPS $100 \%$ ). Figure 5 presents a engine with closed channel. Figure 6 presents a comparison of the pressure measurements in the combustion chamber. 
The next stage of research involved the limitation in the process of air flow of from the cylinder. A non-return valve was installed on the channel to allow air extraction from the cylinder to the environment. As a result of applying this design, during the suction stroke, no air was allowed in the cylinder, whereas during the compression stroke it was possible to decrease the pressure in the combustion chamber. Figure 7 presents the applied $5 \mathrm{~mm}$ orifice with a nonreturn valve and the design excluding this valve, and Fig. 8 contains the results. Involved the introduction of an orifice that provided the possibility of adjusting of the diameter of the $5 \mathrm{~mm}(\mathrm{DCH})$ bleed channel leading into the head and pressure measurement in the combustion chamber for the case as before, i.e. with open (TPS 100\%) and closed throttle (TPS 0\%).

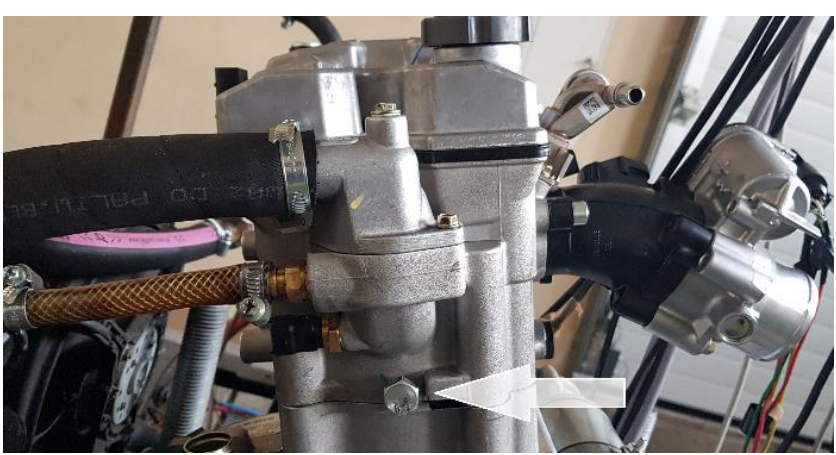

Fig. 5. Engine with closed valve channel

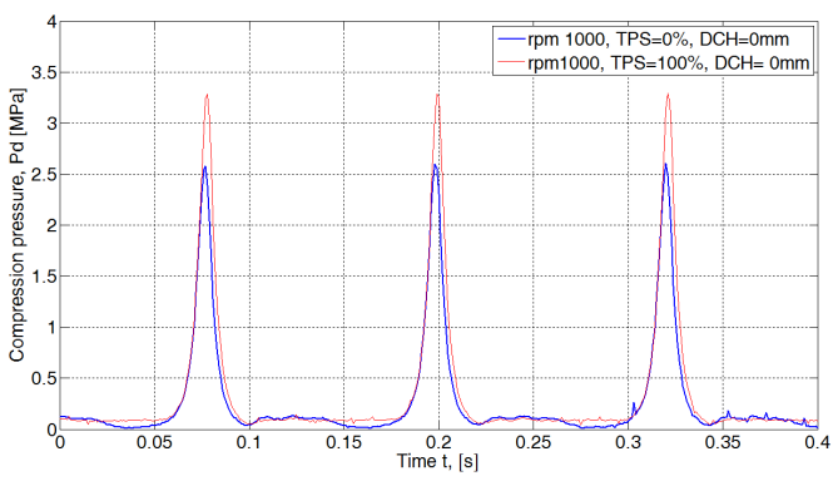

Fig. 6. Pressure curve in the combustion chamber with a closed channel for various throttle opening

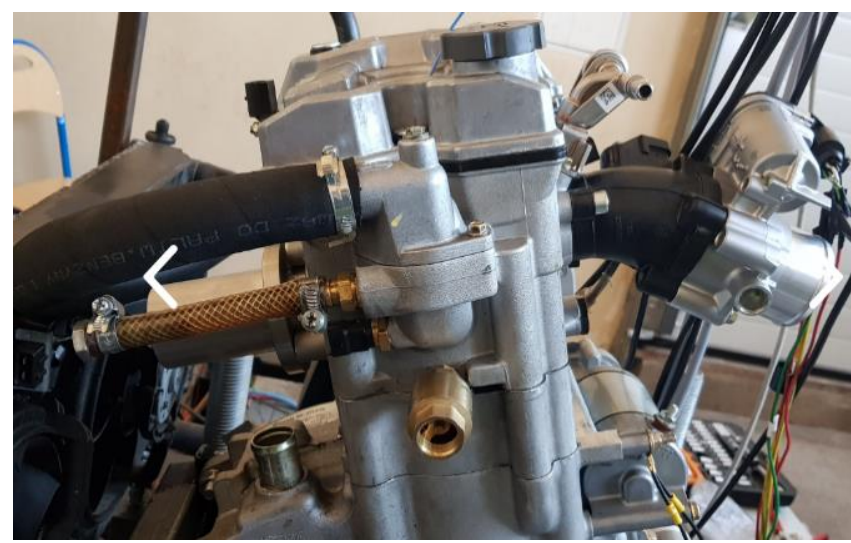

Fig. 7. Cylinder head with an extraction channel with a diameter $5 \mathrm{~mm}$ and non-return valve
The values and the pressure courses summarized in the table confirmed that it is possible control the value of the effective pressure coefficient in the cylinder. The introduction of an additional suitable extraction valve in the engine will provide the control of the compression processes in the engine. Consequently, it will be possible to develop an engine design excluding a throttle that would significantly reduce pressure losses within the low range of rotational speeds. The use of the extraction channel is described in the patent [P.421255].

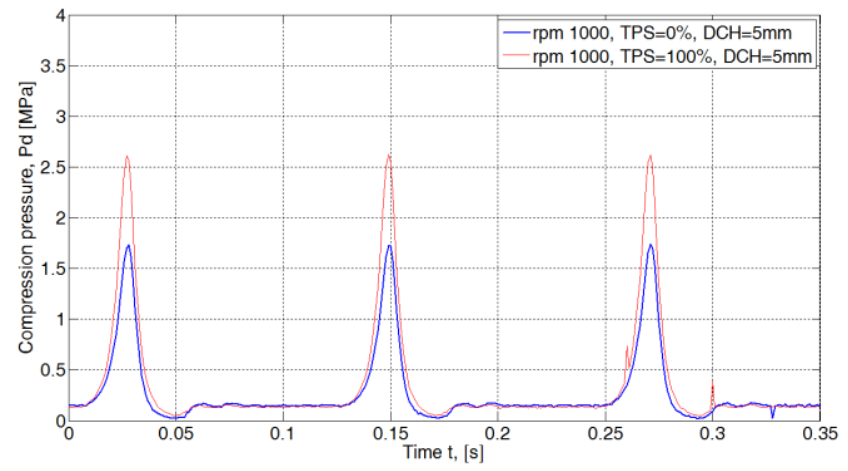

Fig. 8. Pressure curve in the combustion chamber with an orifice with a diameter of $5 \mathrm{~mm}$ for various throttle opening

Table 1. Pressure in cylinder

\begin{tabular}{|l|c|c|}
\hline & $\begin{array}{c}\text { Max pressure } \\
\text { (normal) }\end{array}$ & $\begin{array}{c}\text { Max pressure } \\
(5 \mathrm{~mm} \text { hole diameter })\end{array}$ \\
\hline TPS $0 \%$ & $2.5 \mathrm{MPa}$ & $1.6 \mathrm{MPa}$ \\
\hline TPS $100 \%$ & $3.3 \mathrm{MPa}$ & $2.5 \mathrm{MPa}$ \\
\hline
\end{tabular}

\section{Extraction valve and further potential of con-} trolling the effective pressure in the cylinder

As a result of the installation of an additional, electronically controlled extraction valve would enable the design and development of an engine without a throttle. In preliminary tests, a solenoid valve was installed in the head of the cylinder of the examined ICE at the outlet of the extraction channel. Due to the need to provide high speed of this valve, an inversion of the design of fuel injector was applied, as it was found to operate at adequate frequency ranges. This solution provided the means to control the rate of the increase in effective pressure for unloaded engine, by adjusting the active engine capacity in the compression stroke. Figure 9 contains a photograph of the head with the installed extraction channel applying a fuel injector.

The control of the extraction valve applied ComactRIO controller (cRIO-9032) with an amplifying system, that was developed as dedicated for the purposes of the present study, and based on the IRF Z44N transistor-transoptor logic was used.

As a result of applying an additional crankshaft position sensor, it was possible to transmit a signal that could be employed for determination of the initiation of the compression stroke. Throttle control was designed and achieved by application of Arduino Uno microcontroller. The extraction valve was controlled by developing the proprietary program in the LabVIEW environment. The course of the signal controlling the bleed valve and the signals of the crankshaft position of the engine and the camshaft is pre- 
sented in Fig. 11. TDC position (top dead center) follows 10 impulses of the crankshaft. On the basis of the obtained waveforms, the range of 28 impulses after the TDC of the stroke range was determined as the starting point for the operation of the bleed valve.

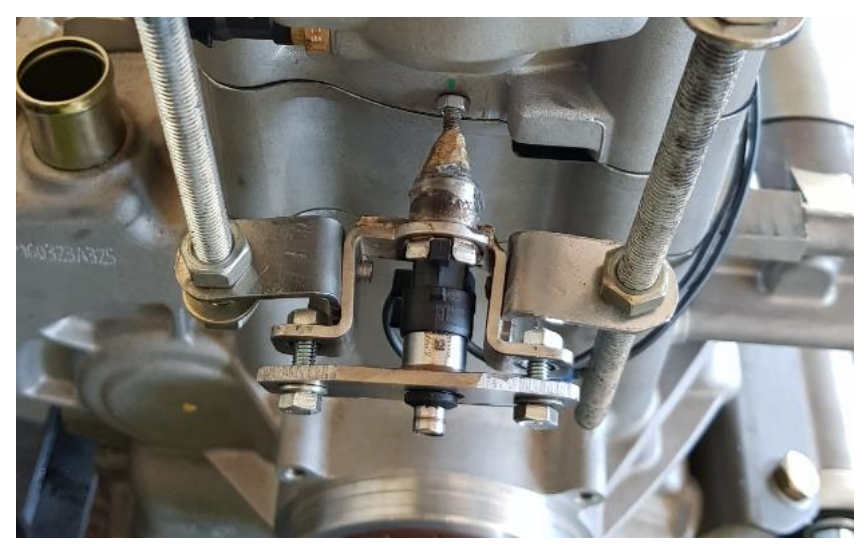

Fig. 9. Cylinder head with extraction channel and installed valve

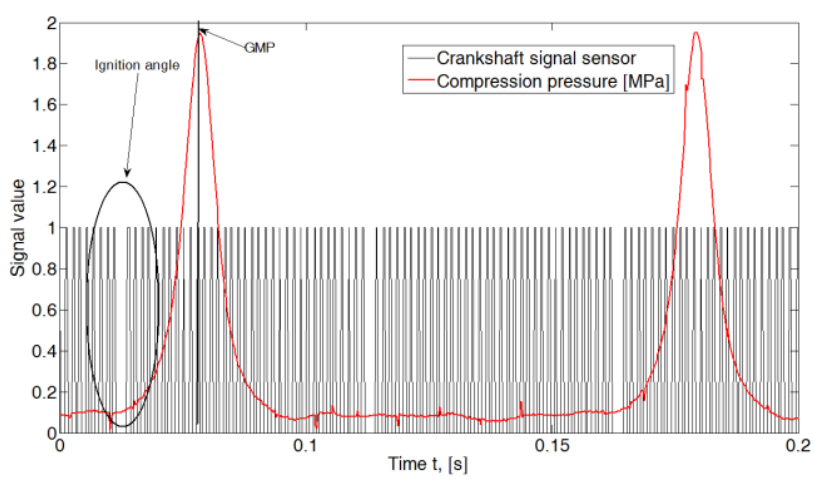

Fig.11 Course of pressure increase in time

In the case of the investigated engine, we have to do with open bleed valve and an open throttle so there is no characteristic pressure drop in the intake stroke (vacuum of pumping loss) and the maximum pressure valve assumed in the cylinder is similar to the case of a closed-throttle internal combustion engine. In the further stage of the research, it is projected to develop a bleed valve that will operate at the frequency of the combustion engine's operation and will be resistant to the conditions in the combustion chamber.

\section{Conclusion}

The objective of the study presented in this paper involved preliminary research on the possibility of reducing pumping losses and controlling the effective pressure increase in cylinder ICE during the charge exchange in the combustion chamber. Attempts to change the effective pressure increase in cylinder ICE and through it the compression ratio have already been undertaken by companies the automotive sector. The most well-known engine designs characterized by variable compression ratios include: MCE5 Engine, Scuderi Engine, SAAB SVC, Infinity VC-T. The biggest disadvantage of such designs is associated with their complexity, as each idea implemented in the engine had to comprise a very large number of components that could have been damaged and were characterized by a very high price. The idea that was reported in the paper with regard to control of the effective pressure increase in cylinder ICE does not need a complex design, as it is relatively cheap, durable and the bleed valve can be located in the spark plug or air injector. These ideas have already been filed in the patent office and the proposed solution includes very limited interference in the existing design of the engine.

The research confirmed the assumption that it is possible to perform smooth and effective control of initiation of the compression stroke. The use of a small orifice with a diameter of $2 \mathrm{~mm}$ resulted in the decrease of pressure in the combustion chamber. It was found that it is possible to apply design changes in order to increase the design compression ratio, e.g. by planning the head, and then controlling the effective pressure increase in cylinder ICE and through it the bleed valve. This solution will allow the engine to adapt to the conditions on the road.

The authors of this paper carry out a number of other tests related to the modification of the engine design, such as resulting from the use of a larger bore size of the bleed valve, application other types of bleed valves to solve the problem with the operating frequency and cooling of the entire system.

\section{Nomenclature}

CR compression ratio

BMC bottom dead center

ICE internal combustion engine
TDC top dead center

TPS throttle position sensor

VCR variable compression ratio

\section{Bibliography}

[1] AMBROZIK, A. Podstawy teorii tłokowych silników spalinowych. Politechnika Warszawska. Warszawa 2012.

[2] AMBROZIK, A. Analiza cykli pracy czterosuwowych silników spalinowych. Wyd. Politechniki Świętokrzyskiej. Kielce 2010.

[3] BIENIEK, A., GRABA, M., HENNEK, K., MAMALA, J. Analysis of fuel consumption of a spark ignition engine in the conditions of a variable load. MATEC Web of Conferences. 2017.
[4] CHANGMING, G., FENGHUA, L., JINGZHEN, S., KANG, W. Effect of compression ratio on performance and emissions of a stratified-charge DISI (direct injection spark ignition) methanol engine. Energy. 2016, 166-175,

[5] DRABIK, D., MAMALA, J., ŚMIEJA, M., PRAZNOWSKI, K. Possibility of reducing $\mathrm{CO}_{2}$ emissions from internal combustion engines. E3S Web of Conferences. 2017.

[6] HARIRAM, V., VAGESH SHANGAR, R. Influence of compression ratio on combustion and performance charac- 
teristics of direct injection compression ignition engine. Alexandria Engineering Journal. 2015, 807-814.

[7] IMARISIO, R., PETERS, B., ROSSI SEBASTIANO, G.M et al. FIAT GM Powertrain: diesel strategies towards fuel neutral European emission standards. ATA Symposium. Bari 2004.

[8] LUFT, S. Podstawy budowy silników. Wydawnictwa Komunikacji i Łaczności. Warszawa 2011.

[9] MAMALA, J. Kompensacja niedostatku siły napędowej w procesie rozpędzania samochodu osobowego. Wydawnictwa Politechniki Opolskiej. Opole 2011.

[10] MAMALA, J., GRABA, M., PRAŻNOWSKI, K., HENNEK, $\mathrm{K}$. Control of the effective pressure in the cylinder of

Dawid Drabik, MEng. - PhD student, Faculty of Mechanical Engineering, Opole University of Technology.

e-mail:drabteam@wp.pl a spark-ignition engine by electromagnetic valve actuator. SAE Technical Paper. Detroit 2019.

[11] MCE-5 Development Tech Letters, http://www.mce-5.com.

[12] MYSŁOWSKI, J. Doładowanie silników. Pojazdy samochodowe. Wydawnictwa Komunikacji i Łaczności. Warszawa 2011.

[13] SOBIESZCZAŃSKI, M. Modelowanie procesów zasilania w silnikach spalinowych. Wydawnictwo Komunikacji Łaczności. Warszawa 2000.

[14] TOMODA, T. Strategies for powertrain development in the era of electric mobility. Forum of 2017 JSAE Annual Congress (Spring) - Powertrain for Passenger Vehicles after 2030. May 2017 (in Japanese).

Prof. Jarosław Mamala, DSc., DEng. - Faculty of Mechanical Engineering, Opole University.

e-mail: j.mamala@po.opole.pl

Krzysztof Prażnowski, DSc., DEng. - Faculty of Mechanical Engineering, Opole University.

e-mail: k.praznowski@po.opole.pl 